BULLETIN Bulletin hispanique

HISPANIQUE Université Michel de Montaigne Bordeaux

115-1 | 2013

Poésie et société en Espagne : 1650-1750

\title{
Producción y consumo poéticos en los conventos femeninos
}

Nieves Baranda Leturio

\section{(2) OpenEdition}

1 Journals

\section{Edición electrónica}

URL: http://journals.openedition.org/bulletinhispanique/2421

DOI: 10.4000/bulletinhispanique. 2421

ISSN: 1775-3821

\section{Editor}

Presses universitaires de Bordeaux

\section{Edición impresa}

Fecha de publicación: 1 junio 2013

Paginación: 165-183

ISBN: 978-2-86781-898-1

ISSN: 0007-4640

\section{Referencia electrónica}

Nieves Baranda Leturio, «Producción y consumo poéticos en los conventos femeninos », Bulletin hispanique [En línea], 115-1 | 2013, Publicado el 01 junio 2016, consultado el 01 mayo 2019. URL : http://journals.openedition.org/bulletinhispanique/2421; DOI : 10.4000/bulletinhispanique.2421 


\title{
Producción y consumo poéticos en los conventos femeninos
}

\author{
Nieves Baranda Leturio \\ UNED Madrid
}

Les couvents féminins de l'époque moderne ont été de grands consommateurs de poésie, non seulement pour des actes liturgiques mais aussi dans leur routine quotidienne. Cette littérature remplit de nombreuses fonctions (festive, didactique, ornementale, consolatrice, dévote et même économique) ce qui explique sa survivance et que protégées par cette tradition, un certain nombre de religieuses aient pu créer une cuvre avec une personnalité propre, étant donné que, loin du coupable orgueil des auteurs, leurs créations étaient jugées au service de la communauté et des fins que cette dernière poursuivait

Mots-clés: poésie, couvents féminins, chant, sociologie littéraire.

Los conventos femeninos de la Edad Moderna fueron grandes consumidores de poesia, no solo para actos litúrgicos, sino también en su rutina cotidiana. Esta literatura cumple numerosas funciones (celebrativa, didáctica, decorativa, consolatoria, devota y hasta económica) lo que explica su pervivencia y que, al amparo de esta tradición, algunas monjas llegaran a crear una obra con personalidad propia, ya que lejos del pecaminoso orgullo autorial, las creaciones se consideraban al servicio de la comunidad y de sus fines.

Palabras claves: poesía, conventos femeninos, canto, sociología literaria.

Spanish women's convents in the Early Modern period were large consumers of poetry, used not only for liturgical purposes but also as part of daily routine. This kind of literature filled various purposes -festive, educational, decorative, consolatory, devotional, and economic even- that explain its survival. Taking advantage of this tradition, some nuns managed to create a personal work, because, far from being considered as a sinful activity of authorial pride, their poems were valued as a service to the community and its goals.

Keywords: poetry, women's convents, music, singing, literary sociology. 
T a aridez de la prosa religiosa, autobiográfica, hagiográfica o cronística Lnos deja en ocasiones escenas que nos permiten participar de un mundo conventual apenas conocido. En el convento de las Franciscas descalzas de Salamanca, al menos durante casi todo el siglo XVII, tenían la siguiente costumbre:

Úsase en esta casa poner el día de la Ascensión un niño Jesús en el coro, rodeado de sus apóstoles y lleno el niño de tantos corazones como ay religiosas, para que los presente al Padre. Esto le pide cada una con palabras tiernas, conforme su afecto, para lo qual hizo esta sierva de Dios otros versos, en nombre de todas, començando el de la madre abadesa ${ }^{1}$.

Sor Manuela de la Santísima Trinidad, que está redactando su crónica en el último decenio del siglo XVII, nos transmite y habla de los poemas que había compuesto muchos años atrás sor Catalina de las Llagas, monja en el mismo convento entre 1605 y 1617. A pesar de que eran poemas para una circunstancia única, construidos a la intención y particular situación de cada una de las monjas participantes en la ceremonia, puestos bajo sus nombres y por tanto sin uso posterior para el mismo fin, el convento había conservado copia y memoria de esta extraordinaria ocasión y así sor Manuela pudo incorporarlas a su crónica. Además añadió unas coplillas que la misma monja había hecho con motivo de su profesión, cantadas a modo de coloquio, mano a mano, con sor María de San Francisco. Es de suponer que todos estos poemas se habían guardado con puntualidad entre los papeles comunitarios, por lo que las monjas debían atribuirles algún mérito o valor, pero sor Manuela se siente en la necesidad de excusarlos: «Bien apartados van los versos de toda curiosidad y arte, pero muy llenos de espíritu y de devoción»².

En efecto, aparte de los habituales cancioneros manuscritos o impresos, recorrer crónicas, vidas y biografías conventuales nos proporciona un buen puñado de textos poéticos compuestos dentro de los claustros, muy alejados de los artificios retóricos de la poesía profesional, pero reveladores de una producción y consumo poéticos que hasta se podrían calificar de intensos por más que carentes en gran parte de originalidad o valor estético. Al igual que sor Manuela, otros biógrafos o autores profesionales reconocen explícitamente esta falta de numen poético cuando reacomodan las obras para su impresión, se excusan destacando en los versillos el valor devoto y el espíritu religioso para

"Este artículo es parte de los resultados del proyecto BIESES, financiado por el Ministerio de Economía y Competitividad (FFI2009-08517) y su continuación (FFI2012-32764).

1. Manuela de la Santísima Trinidad, Fundación del convento de la Purísima Concepción de Franciscas Descalzas de la ciudad de Salamanca, Salamanca: Imprenta de María Estévez, Viuda, 1696, p. 126. Los poemas en p. 125-129; hay edición de la obra en la Biblioteca digital de Castilla y León, accesible desde la web de Bieses. Catalina de las Llagas vivió en el convento entre 1605 y 1617, vid. Ma Fernanda Prada Camín y Mercedes Marcos, Historia, vida y palabra del Monasterio de la Purisima Concepción (Franciscas Descalzas) de Salamanca, Salamanca: Universidad Pontificia, 2001, p. 139.

2. Ibid., p. 129. 
justificar su recuperación escrita, aunque no por ello dejan de engastarlos en sus escritos $^{3}$. Los editores o glosadores entienden que el valor de estas composiciones es indisociable de su contexto de producción y consumo inmediatos, y al sacarlos de él pierden su pleno sentido. Al tratarse de una literatura para un destinatario próximo que pertenece al contexto de la autora y abocada a la desaparición propia de los actos cotidianos y no a la permanencia del arte, su presencia en una obra de recepción pública y pensada para la fama de su objeto $^{4}$ necesitaba ser justificada, de ahí que se aludiera a las circunstancias en las que sirvieron los versos, explicándolos por medio de esa escena con la que pretenden restituirles su valor circunstancial y ante todo religioso, porque ambos eran los signos que marcaban el texto recuperado y publicado como no-artístico, ajeno a la esfera de la creación autorial y sus valores. Esa es la contradicción que subyace a las palabras de sor Manuela, que deja en el aire la pregunta de por qué se han guardado durante casi cien años en el convento los versos de Catalina de las Llagas si están bien apartados del arte y solo servían para las ocasiones expuestas, por qué se copiaron y quién los tenía.

Contradicciones aparte, la explicación de su presencia no artística para nosotros por un lado supone el rescate de unos textos que de otro modo se hubieran perdido definitivamente y por otro nos permite vivificar unos contextos semi-privados de producción y consumo poéticos, procesos de creación y circuitos de comunicación.

\section{LA POESÍA CONVENTUAL EN SU CONTEXTO DE CREACIÓN Y CONSUMO ORIGINARIO}

Como en casi todos los aspectos de la escritura femenina del Siglo de Oro (y su bajo barroco), cuando echamos la vista atrás debemos remontarnos a Teresa de Jesús ${ }^{5}$, especialmente el peso de su carisma, que ejerció una fuerte atracción

3. Por ejemplo, Buenaventura de Arévalo, Vida exemplar y doctrinal de la Venerable Madre Ana de S. Joachin, religiosa Carmelita Descalza en el convento religiosissimo de Santa Ana de la ciudad de Tarazona, Pamplona, Joseph Joachín Martínez, 1736, p. 189; Roque Alberto Faci, Hermosa azuzena y estrella platada y fixa, Zaragoza, José Fort, 1737, p. 243 y p. 250.

4. Las monjas rara vez fueron sujetos de su propio relato en obras impresas, ya que la autobiografía se convertía en biografía por medio de un proceso de reescritura que filtraba y reinterpretaba el texto fuente. En este proceso la monja biografiada se transforma en objeto de consumo cultural, vid. Isabelle Poutrin, Le voile et la plume. Autobiographie et sainteté féminine dans l'Espagne moderne, Madrid, Casa de Velázquez, 1995, p. 251-273.

5. No es posible asegurar que Teresa de Jesús fuera la primera mujer autora de poesía religiosa en España, aunque no conocemos poemas religiosos femeninos anteriores, solo el de Francisca de Silva que aparece en un pliego sevillano de 1542 (Primera justa literaria que después de la muerte del muy magnifico Señor Don Baltazar del Rio, de buena memoria Obispo de Escalas se celebró en el Alholi de los pobres de la ciudad de Sevilla en alabanza de los bienaventurados Sancto Sebastián y Sancto Ysidro). El hecho de que la rúbrica con el nombre de Francisca no merezca ningún comentario adicional sobre el género del autor resulta llamativo en la época, lo que creo indicio de que se tratara de una errata, Francisca por Francisco. En caso de ser una mujer sería el primer poema femenino impreso en una justa. 
modélica en todo lo que se refiere a las mujeres escritoras y sobre todo a las monjas. Frente a la consolidación canónica de que gozó la prosa teresiana desde bien pronto y el amplísimo impacto lector que tuvo, los versos de Teresa de Jesús fueron muy mal conservados y divulgados. Los poemas siguieron manuscritos, casi olvidados salvo dentro de la orden carmelitana (basta comprobar la escasez de copias o la anonimia de algunos) y no se editaron hasta finales del siglo XVIII ${ }^{6}$. Eso no significa que el público en general ignorara que los había compuesto, ya que los mencionaba en la Vida y también en sus cartas, impresas desde 1658 (Zaragoza: Diego Dormer). Por ejemplo, en la Vida-posiblemente la obra más leída e influyente- manifiesta cómo el amor de Dios la lleva a componer poemas: «Yo sé persona que, con no ser poeta, que la acaecía hacer de presto coplas muy sentidas declarando su pena bien; no hechas de su entendimiento, sino que, para más gozar la gloria que tan sabrosa pena le daba, se quejaba de ella a Dios» ${ }^{7}$. Y a su hermano Lorenzo le escribe en 1577 desde Toledo:

Gran fiesta tuvimos ayer con el nombre de Jesús: Dios se lo pague a vuestra merced. No sé qué le envíe por tantas como me hace, si no es esos villancicos que hice yo, que me mandó el confesor las regucijase, y he estado estas noches con ellas, y no supe cómo sino ansí. Tienen graciosa tonada, si la atinara Francisquito, para cantar. Mire si ando bien aprovechada ${ }^{8}$.

Ahora bien, en este aspecto, más importante que su vida escrita fue la institución del tiempo de la recreación dentro de la regla carmelitana. Este marco de ocio conventual fue una novedad, presente desde la primera redacción de las constituciones y conservada en todas las siguientes:

Salidas de comer, podrá la madre priora dispensar que todas juntas puedan hablar en lo que más gusto les diere, como no sean cosas fuera del trato que ha de tener la buena religiosa; y tengan todas allí sus ruecas. Juego en ninguna manera se permita, que el Señor dará gracia a unas para que den recreación a otras. Fundadas en eso, todo es tiempo bien gastado?.

Se trataba de un tiempo cotidiano y predefinido en el que se rompía la rutina y las obligaciones precisas y se descansaba, siempre en forma comunitaria, con conversaciones, cantos, etc. y con indicación de que no se cayera en temas profanos, chismes o asuntos no religiosos en general. La inclusión de la poesía o mejor del canto devoto, aunque no figure explicitada por escrito en las reglas, surgió del interés y complacencia que puso en ello la madre Teresa, cuyo anecdotario y carisma se perpetuó por la orden, difundido primero a sus

6. Si seguimos el catálogo de ediciones que ofrece Antonio Palau, Manual del librero hispanoamericano, Barcelona, Librería Palau, t. XIX, 1967, la primera sería del siglo XVIII. Vid. una breve síntesis bibliográfica del tema en Víctor García de la Concha, El arte literario de santa Teresa, Barcelona, Ariel, 1978, p. 317-318.

7. Teresa de Jesús, Vida, V, 16.

8. A 2 de Enero, cita bien conocida por los estudiosos de la santa de Ávila, tomada de Escritos de santa Teresa, ed. de Vicente de la Fuente, Madrid: Rivadeneyra,, 1861-1862, 2 ts., p. 120.

9. Segunda redacción de 1585, en Obras completas, dir A. Barrientos, Madrid, Espiritualidad, $1984^{3}$, p. 1144; la cursiva es mía. 
discípulas y compañeras más próximas y luego al resto de conventos, hasta hacer de ello una tradición asentada, bien estudiada por los conocedores de su poesía ${ }^{10}$.

La importancia de la huella teresiana en este aspecto se percibe en los poemarios colectivos que conservan algunos monasterios carmelitanos, en especial los más conocidos e importantes cancioneros de Medina de Campo y de Valladolid, que fueron estudiados por García de la Concha y Álvarez Pellitero ${ }^{11}$. Y más allá de la poesía se ha subrayado cómo entre las carmelitas la escritura tuvo siempre una gran importancia, en tanto que era una orden nueva que creaba su historia casi a la vez que venía sucediendo, con una conciencia aguda sobre su propia existencia, su desarrollo y la necesidad de una memoria colectiva autorrepresentativa ${ }^{12}$. La orden carmelitana destaca en este aspecto incluso en un medio donde esa poesía para todo -como la calificó Blecua ${ }^{13}$-, fue un fenómeno generalizado, que englobó a toda la sociedad de la época, obsesionada con los cantares y coplas a lo divino para ahogar en religión la atmósfera pública. Sin embargo, no fue una actividad exclusiva de los descalzos, por más que se subraye como una de sus señas de identidad ${ }^{14}$. La corriente arranca en el siglo XV en otras órdenes y abarca a varias familias, en especial a los franciscanos, como advirtieron Samuel Eiján y Emilio Orozco, que demuestran que fueron ellos los primeros en usarla y persiguen la influencia que su espiritualidad tuvo sobre la mística del Carmelo, que adoptó también este hábito de devoción, individual y compartida ${ }^{15}$.

10. La bibliografía es ciertamente extensa, pero no cabe olvidar estudios clásicos como Víctor García de la Concha, op. cit., p. 317-376, y Emilio Orozco, Poesía y mistica. Introducción a la lírica de san Juan de la Cruz, Madrid, Guadarrama, 1959, p. 115-158; además vid. Pedro Ruiz Pérez, «Santa Teresa de Jesús: Pragmática y poética», en Ma Jesús Mancho (ed.), La espiritualidad española del siglo XVI. Aspectos literarios y lingüísticos, Salamanca: Universidad, 1990, p. 185-191. Sobre la difusión de esta poesía en los conventos de Francia habrá que esperar a los trabajos que Daniel Hanna está realizando en la actualidad, aunque cabe recordar la tempranísima traducción publicada hacia 1668, que cita Palau, op. cit., no 299291.

11. Víctor García de la Concha y Ana Ma Álvarez Pellitero (eds.), Libro de romances y coplas del Carmelo de Valladolid (c. 1590-1609), Valladolid, Consejo General de Castilla y León, 1982; y Ana Ma Álvarez Pellitero, "Cancionero del Carmelo de Medina del Campo (1604-1622)”, en Teófanes Egido, Víctor García de la Concha y Olegario González de Cardedal, Olegario (eds.), Actas del congreso internacional teresiano. IV centenario de Santa Teresa de Jesús, Salamanca, Universidad de Salamanca, etc., 1984, p. 525-543.

12. Vid . Isabelle Poutrin, op. cit., y por ejemplo Concha Torres, La clausura femenina en la Salamanca del siglo XVII. Dominicas y carmelitas descalzas, Salamanca, Universidad, 1991.

13. Blecua, "Fernando de Herrera y la poesía de su época», en Francisco Rico (dir.), Historia y crítica de la literatura española, Barcelona, Crítica, 1980, t. II, p. 426-427.

14. Así lo afirma Isabel Morujão, Por tras da grade: poesia conventual feminina em Portugal (Sécs. XVII-XVIII), Tesis doctoral, Porto, 2005, p. 93, que destaca la incomprensión de los calzados ante unas monjas que hacen versos y coplas.

15. Samuel Eiján, La poesía franciscana en España, Portugal y América (siglos XIII-XIX). Historia y antología, Santiago de Compostela, Tip. de El Eco Franciscano, 1935, caps. 5 y 6; Emilio Orozco, op. cit. 
Otras órdenes femeninas entienden el valor psicológico de la recreación y la incorporan a sus reglas, para lo que no necesitan darle el mismo nombre, sino aludir sencillamente a un tiempo de conversación libre, dentro del silencio que domina en el régimen conventual:

las sorores flacas y enfermas y las que las sirven por la recreación y servicio de ellas podrán hablar en la enfermería; esso mismo en las fiestas dobles y solemnidades de los Apóstoles. Y en algunos otros días que a la abadesa pareciere, en cierto lugar para esto diputado, desde hora de nona hasta vísperas o en otra hora convenible puedan las sopores hablar de Nuestro Señor Jesucristo y de la solemnidad de la fiesta y de algunos piadosos ejemplos de santos y de otras cosas lícitas y honestas ${ }^{16}$.

Con ese tiempo de palabra en libertad también incorporan, siquiera de forma indirecta, el uso de los cantares y coplas para su recreo.

Mariana de San José (1658-1638) recuerda como un punto de inflexión en su vida la llamada de Dios, sentida cuando siendo muy niña recibió la bendición de Santa Teresa. Había nacido en Alba de Tormes, lo que no es irrelevante para estos efectos. A partir de 1603, cuando funde la Recolección Agustina tendrá muy presente a la madre carmelita cuyo proceso de beatificación ya estaba en curso, y aparte de instaurar una recreación, fomentará el uso de coplas en la cotidianeidad conventual, compuestas y compartidas entre las monjas. Leticia Sánchez señala cartas de 1610 y 1627 en que anima a las monjas a componer coplas e intercambiarlas entre los conventos: ella misma las envía de Palencia a Valladolid, porque le parecen muy buenas, o hace llegar a Castilleja las que se compusieron en Madrid con motivo de la fiesta de la presentación de la Virgen ("fiesta de la Niña») en $1627^{17}$. En su actuación encontramos prueba de que no fue solo una recomendación, sino una actitud decidida de apuesta por esta forma devocional.

La estricta clausura impuesta a las religiosas después del Concilio de Trento, que les impedía salir fuera del convento o recibir visitas no autorizadas, no cortó la comunicación con el exterior ni mucho menos. Las monjas pertenecen con frecuencia a las familias del entorno urbano del convento en que profesan, participan de las corrientes estéticas de su tiempo, de sus debates y ansiedades, inmersas en el mundo civil vivo que las rodea, próximo o lejano. La correspondencia, las conversaciones en la reja, las predicaciones, visitas, etc. son medios que las mantienen al día, incluso sin estar cerca de los núcleos de poder, como pueden mostrar la venerable sor María de Jesús viviendo en Ágreda o la muy ilustre Luisa Manrique de Lara, que se encierra en el convento de carmelitas descalzas de Malagón en Ciudad Real. La poesía forma parte de

16. Regla de las sorores y monjas de la gloriosa madre santa Clara, dada y confirmada por la santidad de Urbano cuarto de felice memoria, s.l., s.n., s.a., h. 12v., dada en enero de 1624 en Madrid (Biblioteca digital hispánica).

17. «Vida cotidiana y coordenadas socio-religiosas en el epistolario de Mariana de San José (1603-1638)», en Gabriella Zarri y Nieves Baranda (eds.), Memoria e communità femminili. Spagne e Italia, secc. XV-XVII. Memoria y comunidades femeninas. España e Italia, siglos XV-XVII, Florencia/ Madrid, Firenze University Press/ UNED, 2011, p. 87-109, en p. 98. 
este trasiego informativo e incluso formativo, oral y escrito, que intercambian las monjas con quienes las rodean y con otros conventos y en este sentido cuando toca temas religiosos resulta particularmente apta para ser incorporada a su modo de vida. Las cartas, sin duda, eran un lugar privilegiado para cruzar estos versos, al igual que lo hacía Teresa de Jesús. La costumbre no se limita a las carmelitas descalzas, según demuestra María de la Antigua, primero clarisa y luego mercedaria: «Estava el otro día después de san Bernabé pensando que este romance que hize (o por mejor decir, me hizieron que hiziera); no lo quería enviar a manos de V. M. por ser cosa que yo jamás la he hecho y averme parecido siempre mal, por ser ya en mugeres y aún averla tachado por buena que fuesse...» ${ }^{18}$. O Ana de san Jerónimo, francisca descalza, que remite a las agustinas del Corpus Christi unas coplas para agradecerles una imagen de santa margarita de Cortona y unos poemas a otra monja a la vez que le envía dos estampas y un libro ${ }^{19}$.

Como escritoras o poetas, las monjas no son en ningún caso iniciadoras de tradiciones poéticas, pero en cambio participaron en todas las corrientes de poesía religiosa que se desarrollan a partir de la segunda mitad del $\mathrm{XVI}^{20}$ : versiones de los salmos ${ }^{21}$, poesía petrarquista a lo divino ${ }^{22}$, los cantos devotos, la estética del conceptismo sacro y el romancero espiritual ${ }^{23}$. En particular fueron estas dos últimas modalidades estéticas, sin duda por ser las más populares en la época, las que vemos dominar los escritos poéticos de las monjas, en los que solo las autoras más cultas o con una mejor vena poética se adentran por caminos de mayor compromiso y exigencia estética. Y es que en esa porosidad informativa que se da entre el claustro y la calle es imposible que toda esa lírica devota, la del cantar y la copla divinizados, al servicio de una intención

18. María de la Antigua, Desengaño de religiosos, y almas que tratan de Virtud, Sevilla: Juan Cabezas, 1678, p. 75, precede al romance «Dulce Jesús de mi vida» Sobre la relación de esta monja con la escritura vid. Carlos Álvarez Santaló, «Algunos usos del libro y la escritura en el ámbito conventual: el Desengaño de religiosos de Sor María de la Antigua (1614-1617)» en Carlos A. González Sánchez y Enriqueta Vila Vilar (eds.), Grafias del imaginario: Representaciones culturales en España y América (siglos XVI-XVIII), México, Fondo de Cultura Económica, 2003, p. 157-203.

19. Ana de san Jerónimo, Obras poéticas, Córdoba: Juan Rodríguez, 1773, p. 253 y p. 219

20. Sigo, como no podía ser menos, a Valentín Núnez, «La poesía religiosa del Siglo de Oro. Historia, transmisión y canon», Begoña López Bueno (dir.), En torno al canon: aproximaciones y estrategias, Sevilla, Grupo PASO, Universidad de Sevilla, 2005, p. 333-370

21. Cecilia del Nacimiento, del salmo 49 y del 113, vid. Obras completas, ed. de J. M. Díaz Cerón, Madrid, Espiritualidad, p. 625-631. Más prosaica es la versión de María de la Asunción con sus «Endechas explicando el Psalmo 87 que comiença Domine Deus salutis mea», en Manuela de la Santísima Trinidad, op. cit.., p. 125-126.

22. Vid. una completa relación bibliográfica de estudios en Bieses. Entre ellos destaco, por tratar específicamente el tema, Ma Pilar Manero Sorolla, "La poesía de María de San José (Salazar)", Estudios sobre escritoras hispánicas en honor de Georgina Sabat-Rivers, Madrid: Castalia, 1992, p. 182-222.

23. Estas últimas corrientes son las más comunes entre la poesía de monjas, como se verá a lo largo del presente trabajo, lo que me evita citar ahora nombres precisos. 
didáctica y anzuelo para una devoción directa y afectiva, se quedara fuera ${ }^{24}$. Así las corrientes de poesía claustral no hacen más que reflejar una realidad poética que se deriva de la sociedad de su tiempo y que interactúa con ellas.

Sin embargo, igual que en la sociedad civil los poemas se presentan en contextos precisos, también el claustro tiene sus nichos específicos para el verso, que bien por creación de las monjas, por apropiación de textos ajenos o por encargo especializado, sirven a propósitos comunitarios o individuales. Recordemos, como muestra de este origen diverso de los textos poéticos destinados a un fin altamente especializado y característico de los conventos femeninos, el caso de los poemas a las tomas de velo, que se utilizan en la ceremonia litúrgica y que son compuestos por encargo. Unos, circularon en pliegos sueltos o incluidos en compilaciones de algunos autores famosos, pero otros fueron hechos asimismo por monjas, y han quedado entre las poesías de Teresa de Jesús y otros muchos libros y cartapacios ${ }^{25}$. O los versos en paredes, cancioneros sobre yeso, donde se puede dar un traslado fluido entre lo propio y lo ajeno, del que son ejemplo palmario tantos cartapacios sobre papel con poesía anónima: «En casi todas las puertas de las oficinas del convento tenía puesta la sierva de Dios de su propia letra algunas poesías de muy grande espíritu que movían a devoción: algunas eran ajenas; entre las cuales, las que hoy perseveran son del tenor siguiente...». Y continúa su descripción fray Juanetín Niño con algunos de los versos que tenía tan utilitariamente pintados sor Ana María de San José (1581-1632), clarisa en Salamanca, una suerte de curso didáctico que orientaba el buen uso del espacio a modo de mapa para el alma, según ilustra este ejemplo «En la puerta de un desván está otra que dice así: "Quien busca por los rincones/ aquel que es Dios escondido/ si le busca con amores,/ hallarlo ha de amor vencido" ${ }^{26}$.

Aunque dado el carácter abierto para el diálogo y el esparcimiento de la recreación podría creerse que la mayor parte de los versos conservados se refieren a esos momentos, lo cierto es que las fuentes son parcas en ese aspecto. No conviene olvidar que las biografías de monjas se orientan a la construcción de una imagen penitencial, para lo cual la recreación no ofrece episodios de carácter adecuado. Así en algunas alusiones a los poemas compuestos en este momento se subraya que sirven para refuerzo de la comunidad y su espíritu religioso. Los versos de la fundadora de las agustinas recoletas, Mariana de San José, cumplen funciones terapéuticas para el alma y el cuerpo: destierran melancolías, llenan los corazones de gozo y alientan a mayor perfección ${ }^{27}$; y entre las carmelitas descalzas de Malagón, la gracia que despliega Luisa Magdalena de Jesús (de seglar Luisa Manrique de Lara, Condesa de Paredes -1604-1660-), no es más que obediencia al mandato de santa Teresa, «porque dice nuestra santa Madre en sus libros que el alegrarse en las recreaciones con sus hermanas también es

24. M. Frenk, «Lírica popular a lo divino», Edad de Oro, VIII, 1989, p. 107-116.

25. Vid. Nieves Baranda, «Cantos al sacro epitalamio o sea pliegos poéticos para las tomas de velo", Bulletin Hispanique, 113, 1, 2011, p. 269-296.

26. Apud Samuel Eiján, op. cit., p. 192 y p. 193.

27. Alonso de Villerino, Esclarecido solar de las religiosas recoletas de nuestro padre san Agustín y vidas de las insignes hijas de sus conventos, Madrid, Bernardo de Villadiego, 1690, II, p. 18 
amor perfecto $»^{28}$. Por eso son más explícitas que las biografías algunas rúbricas que aluden a estos momentos piadosamente lúdicos y a veces los alegran con un texto de tono jocoso y autorreferencial: «Haviéndole dicho que para la recreación hiciera algo, contando su entrada hizo estas coplas: Pues que quieren mis madres/ que las recree,/ yo les contaré un cuento/ como pudiere» ${ }^{29}$. Son encargos que quieren subrayar con la poesía ciertas ocasiones celebrativas para su pequeña historia y la comunidad echa mano de versificadoras reconocidas y les manda componer poemas: "Al Santísimo Christo de la Piedad, quando le baxaron de su altar para tomar la medida de los espejos, que en el ínterin nos le pussieron en la rexa el Padre D. Julián Sánchez Escudero, que assistía. Fue víspera de San Pedro y se cantó éste en recreación ${ }^{30}$. Pero cuando la monja poeta es realmente hábil y apreciada, el encargo no se detiene en estos fines domésticos. Incluye sor María de Santa Isabel en su cancionero manuscrito un villancico que se cantó en 1642 en la iglesia ${ }^{31}$, y si parece que otros debieron ser de encargo, por ejemplo, para tomas de velo, no queda explícito. Sor Francisca de Santa Teresa (1645-1709), trinitaria en Madrid y coetánea de sor Marcela de San Félix, la hija poeta de Lope de Vega, deja en sus rúbricas constancia de esta presión para componer versos, exigidos desde dentro, pero también para el exterior, en parte moneda de intercambio por los favores que recibía el convento y muestra de la red de clientelas y mecenazgos a la que pertenecía la comunidad, ya que los encargos atienden a necesidades, el pago de favores o el cumplimiento con el padre ministro, el capellán, los marqueses de La Laguna ${ }^{32}$ o la fundadora de una capellanía, casi siempre en relación a acontecimientos religiosos, pero no exclusivamente: "Estas dos letras a los gloriossíssimos mártires San Justo y Pastor; y las que se hallaren en este Libro las hiçe en diferentes ocasiones de mandato del señor Doctor Don Gabriel Sanz, su cura propio y visitador de los conbentos sujetos a su Eminencia. Romance para su día», "Al cumplimiento de los dos años de la Sra. Da María Rosa de la Çerda Téllez Xirón, hija de los Excellentíssimos señores Don Ioseph Manrrique de la Cerda y de Da Manuela Téllez Xirón, Marqueses de la Laguna, se los da la autora en estas coplas». Una de esta rúbricas muestra cómo la necesidad social de la congregación se podía imponer a las circunstancias personales, lo que

28. Agustín de Jesús María, Vida y muerte de la Venerable Madre Luisa Magdalena de Jesús, Madrid: Antonio González de Reyes, 1705, p. 149.

29. Ana de San Jerónimo, op. cit., p. 224-227. No es la única ocasión en que se documenta que alguna novicia o monja recibiera la orden de componer un poema para cantar en recreación, como le sucede a sor María Francisca de San Antonio, Hermosa azuzena, y estrella plantada y fixa en el suelo, y cielo del convento del Orden de la Purissima Concepción de la Villa de las Cuevas de Cañarte..., Zaragoza, Joseph Fort, 1737, p.244, que alude a esta obligación en su poema: "Qué queréis Señor que haga/ siendo compelida oy...»

30. Poesias de la madre sor Francisca de Santa Teresa, religiosa trinitaria descalza en la villa de Madrid, manuscrito del siglo XVII, conservado en el convento, ff. 172r-174v.

31. «Para lograr la música de la primera copla y del estribillo que no escrevi yo, me pidieron hiçiese a propósito las demás coplas para la natividad de Cristo. Cantósse en la yglesia año 1642 en Toledo", María de Santa Isabel, Poesías, Biblioteca Nacional, Ms. 7469, h. 52v.

32. Patronos del convento desde 1630, sus escudos campean en la actual fachada. 
quizá le resultó a la autora lo bastante enojoso como para dejar constancia: «Haviendo fundado dońa Fabiana Soriana una Capellanía en su hijo D. Iuan Antonio de los Reyes, hermano de Sor María de Santa Gertrudis, fundósse en el Altar del Santíssimo Christo de la Piedad, y el día que tomó la posesión [...] me mandaron escribir, teniendo mala la mano derecha ${ }^{33}$.

La vida conventual es en su conjunto muy rutinaria, dado que la estricta distribución del tiempo a lo largo del día marca un compás donde apenas queda margen para lo accidental o sorpresivo. No obstante, a lo largo del año se producen ocasiones celebrativas, unas propias del ciclo litúrgico, otras provocadas por la dinámica institucional y otras sobrevenidas desde el exterior. Para expresar colectivamente la alegría inherente a estas celebraciones los conventos recurrían habitualmente al canto o a una actividad lúdica comunitaria, en la que subyacen elementos literarios.

Aparte de las celebraciones que tenían que ver con las inauguraciones de capillas o nuevos ornamentos del culto, como las que le pedían a Gregoria Francisca de Santa Teresa, de puertas afuera, es decir, en la iglesia, las tomas de velo eran las ceremonias comunes más importantes. En ellas parece que eran imprescindibles los villancicos, al menos desde la segunda mitad del siglo XVII, incluidos como parte de la ceremonia y cantados por las monjas o por ejecutores profesionales. Las letras de estos textos eran compuestas ex profeso para la ocasión, porque incluían elementos de alusión personal, basados casi siempre en juegos de palabras o alegorías que amplificaban el nombre de la nueva monja o de su familia. En la mayor parte de las ocasiones estos poemas son anónimos y debemos sospechar, a partir de los casos conocidos, que compuestos por encargo por algún poeta local. No obstante, también podían ser obra de alguna monja, poeta aventajada, en el propio convento, en alguno próximo o por la misma novicia ${ }^{34}$. Pero la ceremonia pública era solo una parte del conjunto de actividades en torno a estas celebraciones, que luego se prolongaban en el interior y ya de modo mucho más informal: en unos casos por medio de representaciones dramáticas o paradramáticas, como las que conocemos de sor Marcela de San Félix, Gregoria Francisca de Santa Teresa o Cecilia del Nacimiento y María de San Alberto. Incluso en formas más humildes, Mariana de Jesús nos demuestra que se abrían espacios a la improvisación y la ruptura de la rigidez del silencio con el canto de coplas improvisadas. Como estaba obligada a ocuparse de las tareas de cocina el día que profesó una religiosa que ella había educado como novicia:

33. Poesías de la madre sor Francisca de Santa Teresa, op. cit., para la localización exacta de estas citas, vid. Bieses

34. Este sería el caso de sor Catalina de las Llagas, que escribe versos luego cantados a medias con la M. María de San Francisco, en Manuela de la Santísima Trinidad, op. cit., p. 125; o de Elvira del Nacimiento (c. 1572-1638), que escribió tres poemas para el día de su profesión (BNE, Ms. 12958(62), fols. 4v-5r.). vid. Emeterio de Jesús María, «Ensayo sobre la lírica carmelitana hasta el siglo XX», El Monte Carmelo, 50, 1949, p. 59-60. 
salió al refitorio cantando estos versos: "Pues que no hos puedo servir [..]" De aquí iba prosiguiendo muchos versos que su espíritu le dictava y las religiosas todas estavan tan edificadas de verla que cada una le quisiesse quitar el travaxo si les diera permissión ${ }^{35}$.

El año litúrgico contaba con festividades que se celebraban informalmente de puertas adentro. En algún momento habrá que detenerse en elaborar un catálogo de los tipos de celebraciones conventuales, pero por ahora cabe relacionar algunas que conocemos con más detalle a partir de estas fuentes hagiográficas, autobiográficas y cronísticas. En el convento de Carmelitas descalzas de Malagón: «Las pascuas de navidad suelen festexar nuestras monjas al nińo recién nacido y a su madre santísima con algunos autos a propósito y entremeses para alegrar la comunidad. Y como la madre [Luisa Magdalena de Jesús] componía tan bien, trazaba estas fiestas componiéndolas acomodadas a las religiosas.... ${ }^{36}$. Son muchas las noticias sobre representaciones para festejar, que dan lugar a una larga gradación desde las piezas dramáticas con texto y estructura formal de diálogo hasta los festejos en que las religiosas van recitando o leyendo sucesivamente sus coplas o sencillamente hacen una procesión en la que cantan ${ }^{37}$. Las franciscas descalzas de Granada celebraban con particular refinamiento algunas fiestas. Para la Concepción «en la puerta de el refectorio este día se pusieron dos tarjas, en la de mano derecha pintadas las llagas de Christo con una cruz y esta letra "Preserbada", en la tarja del lado izquierdo la de N.P.S. Francisco con un brazo y esta letra "Defendida" y en medio esta copla ${ }^{38}$. El domingo de ramos en el refectorio se invitaba a comer a Jesús (la llamada «mesa del nińo»), «en memoria de no haver tenido Jesús quien lo convidase en Jerusalén». Se ponía un altar con el niño y en la mesa cuatro figuras, que representaban los cuatro elementos llevando comida, cada uno con un cartel con una copla; se ponían otras coplas en la capa del nińo, en la servilleta y repartidas por la mesa de las monjas, referidas a palabras del evangelio ${ }^{39}$. Las trinitarias, que tenían poetas de renombre como sor Marcela o sor Francisca de Santa Teresa, celebraban las navidades con coloquios, el año nuevo con una tonadilla, el día de la santa cruz de mayo con la «obligación antigua» de que todas compongan versos, en adviento por el sorteo que se hacía para ver quién guardaba el sueńo del nińo Jesús, otros poemas eran para la festividad de san Cayetano ${ }^{40}$. En navidades en el convento de Agustinas

35. Vida de la venerable madre Mariana de Jesús Religiosa de la primera regla de santa Clara en el convento de la [sic] Descalzas Franciscas de san Antonio de la Ciudad de Trujillo, BNE, Ms. 7999, ff. 98v-99r.

36. Agustín de Jesús María, op. cit., p. 150-151.

37. Una de sus formulas más sencillas sería la que recogíamos al comienzo a propósito de sor Catalina de las Llagas, que asigna unos versos a cada monja, dramatizando así un acto conventual.

38. Ana de san Jerónimo, op. cit.., p. 207.

39. Ibid. p. 158-170. Son tres las «mesas del niño» editadas en las obras de Ana de San Jerónimo, siempre con variaciones decorativas y con poemas distintos, la tercera se data en 1743 , por lo que las otras dos deben ser anteriores.

40. Esta relación de celebraciones sigue las rúbricas de los poemas de sor Francisca de santa Teresa, conservados en un manuscrito en el convento de Trinitarias de Madrid y otro en la 
recoletas de Salamanca hacen un festejo trasladando en procesión una imagen de la Virgen y otra de San Josés ${ }^{11}$. En todos estos casos el verso, cantado, recitado o actuado estaba presente de algún modo.

Con menos poesía, formalización y complejidad se mencionan otras celebraciones en conventos humildes, como las carmelitas calzadas de Piedrahita, donde la presencia del canto y el baile parece considerarse un elemento constante de todas las festividades anuales:

Suelen las religiosas mozas entretenerse y divertirse los días festivos y principales de el año con licencia de sus preladas y tocando varios instrumentos bailan con la honestidad y recato correspondiente a su estado, y no al estilo de minuetes y otros diversos y lascivos bailes que el diablo ha introducido en España, para ruina espiritual de muchas almas. Pues el día de la natividad de Christo, año nuevo y día de nuestra madre y señora del Carmen, iban a la quadra de la venerable virgen [María de Jesús] y sacavan de sí a la venerable anciana y la cýtara de su cuerpo, que siempre estava tocando el tono de penitencia, la templava a tono de júbilo y regocijo, tomava la serrana el instrumento y tocándole bailava con las demás religiosas, y cantavan a una imagen de nuestra señora del Carmen muy hermosa que se registra desde la quadra de la Venerable Virgen, los versos siguientes... ${ }^{42}$.

Aun siendo un testimonio particular, la falta de una reglamentación precisa para esta celebración, basada solo en las ganas de las jóvenes de cantar y bailar, pone en evidencia que a pesar de la limitación de los testimonios particulares recogidos, podríamos considerarlo una realidad frecuente para muchos conventos de la época. Lo que se desprende de los datos es que casi cualquier motivo podía dar pie al uso de un texto poético, y eso solo se explica a partir de una convivencia natural y cotidiana con el verso devoto. Por ejemplo, se escriben poemas a imágenes: Luisa Magdalena de Jesús (Enríquez de Lara) compone un poema a una escultura del salvador ${ }^{43}$, Gregoria Francisca de Santa Teresa (16531736, OCD Sevilla) a un ecce homo ${ }^{44}$, las monjas de Santa Clara de Trujillo reciben con poemas una imagen modelada sobre una visión de sor Mariana de Jesús ${ }^{45}$; Ana de San Jerónimo «A una imagen de Jesús niño llevando la cruz a el ombro y una oveja asida de una traílla, que lo sigue, vuelta el niño la cabeza a la oveja; se cantó la nochebuena» ${ }^{46}$. Esta función de coplas y cantares se asimilaba durante el noviciado, porque podían formar parte de los ejercicios que la maestra empleaba

Biblioteca de la Universidad de Oviedo; una relación completa de ambas fuentes en Bieses.

41. Lo sabemos porque se nos cuenta que Mariana de San José (1585-1654, ORSA), a pesar de estar muy enferma, sintió un impulso «y saliendo fuera de la celda dando saltos de placer, passó adelante acompañando las imágenes dançando, llena de alegría y cantando lo que sigue: "Un contento me bulle acá dentro [...]". A este modo fue haziendo otras con suma admiración de las religiosas", Alonso de Villerino, op. cit., T. II, p. 18.

42. Vida de la venerable madre Maria de Jesús, religiosa de la vida activa en el religiosissimo convento de nuestra madre, y señora del Carmen de la Villa de Piedrahita, Salamanca, Sebastián de Estrada, 1720, p. 377-378.

43. Agustín de Jesús María, op. cit., p. 180.

44. Francisca de Santa Teresa, op. cit., p. 51.

45. Vida, op. cit., f. 23r.

46. Ana de San Jerónimo, op. cit., p. 153. 
para educar a las futuras monjas, a veces de una forma directa, como sabemos que hizo Mariana de San José, (1585- 1654). Tenía luchas con el demonio, al que presentaba batalla: «y los carteles de desafío ponía en verso y manda a sus novicias que los cantasen. Uno de ellos era este: 'No te metas conmigo/ fiero patillas/que por Christo [he] de darte/ mil zancadillas» ${ }^{47}$. Pero en esa función participaba toda la comunidad, por eso Gregoria Francisca de Santa Teresa dedica unas coplas a una novicia que estaba tentada de volver al siglo: «Para que recobrasse el aliento, que la hurtó la fatiga de la porfiada tentación....»4. Más frecuentemente el didactismo queda registrado solo en los textos, donde se puede expresar por medio de los imperativos, al estilo empleado por Ana de San Jerónimo en las coplas "Para las suertes de año nuevo»" ${ }^{49}$, que exhortan a las monjas a aceptar lo que les depare el sorteo. O el «Romance que la bendita madre [María de la Antigua] escrivió a tres hijas suyas espirituales que después de su salida para el convento de Lora quedaron en el de Santa Clara de Marchena, muy afligidas y solas» ${ }^{50}$, que hace de la despedida una exhortación didáctica. Otras monjas componen versos para educar a sus compañeras con una clara función didáctica. María de la Antigua en los "Amorosos coloquios que manda mi seńor escribir para enamorar las almas de sus esposas a su trato y conversación en el silencio y desamparo de todas las cosas criadas y en la soledad acompañada con él solo... Irá como su majestad lo ordenare. Aquí me dixo [Dios] que algo irá en verso y lo demás razonado" " ${ }^{51}$. Posiblemente la retórica de la humilitas solo permitía una enseñanza directa a ciertas monjas del convento, quizá cuando desempeñaban cargos en la comunidad, así se recurre a formas oblicuas, que incluyen destinar las admoniciones a uno mismo, según hizo Ana de San Agustín, que a raíz de una visión donde se le decía que moriría antes de los ochenta ańos creó una coplilla ¿̇consolatoria?: «y para tener un despertador que le acordasse esta dicha, quando el vivir le era penoso, puso en su celda en cifra esta revelación en una cuartilla que dezía assí: "Poco menos son de ochenta/ los que contra mi pelean/ ruego a Dios mis ojos vean/ presto el fin de aquesta qüenta”. Quando entraban en su celda las religiosas, les dezía leyéndoles esta copla que no hallava otro mayor consuelo en sus cuidados y ahogos $»^{52}$.

47. Alonso de Villerino, op. cit., II, p. 18.

48. Diego de Torres Villarroel, Vida exemplar de la venerable madre Gregoria Francisca de Santa Teresa, Madrid, Viuda de Ibarra, 1798, p. 17, el poema, que comienza «Tortolilla que a tu amante», en p. 18-19, la autora murió en 1736.

49. Ana de San Jerónimo, op. cit., p. 279-282. Estos sorteos se explican en el Ritual de las monjas agustinas recoletas, Madrid, Augustinus, 1987, p. 61, y consistían en asignar a cada religiosa y para todo el año: un santo, una virtud y una necesidad de la iglesia por la que tendrá que rezar.

50. María de la Antigua, op. cit., p. 812-814.

51. Ibid. p. 410; siguen poemas en redondillas intercalados con comentarios en prosa donde habla Dios y le dice lo que debe tratar en el poema.

52. Alonso de San Jerónimo, Vida virtudes y milagros de la prodigiosa virgen y madre Ana de San Agustín, Madrid, Francisco Nieto, 1668, f. 244v.-245r. 
Sor Ana de san Agustín colgaba estos versos en la pared de su celda, pero no es la única que emplea coplas para la decoración mural, a veces de modo permanente, otras para ciertas festividades. Las franciscas descalzas de Granada para celebrar la Concepción, como ya hemos visto; en Monforte de Lemos, las clarisas decoraron un extenso altar para celebrar a la Inmaculada, donde además de las imágenes incluían versos compuestos por sor Cándida de la $\mathrm{Cruz}^{53}$. En estos casos la poesía ha traspasado el límite interior para hacerse visible a los fieles que visitan la iglesia, lo que no era raro, si bien por lo general carecemos de datos sobre la autoría de esos poemas decorativos, que solo en ocasiones interesa a nuestras fuentes. Por ejemplo, "Al Santísimo, que, saliendo de San Luis a visitar a los enfermos, entró en el Convento de la Concepción de religiosas franciscas, de el Cavallero de Gracia, en donde ofrecieron a su majestad, en un ramo, estas dos quintillas ${ }^{54}$, ¿las hicieron las monjas del convento? ¿las encargaron? La misma duda plantean las que usaron las capuchinas de Madrid para pedir limosna, según se desprende de las rúbricas de algunos poemas: "Aguinaldo que pide el Niño Jesús de las madres capuchinas», «Limosna de ferias que pide el Niño Jesús de las madres capuchinas de Madrid», "Ferias que pide el Niño Jesús de las madres capuchinas de esta corte», "Cera para el monumento que pide el Niño Jesús de las madres capuchinas de Madrid. Coplas» ${ }^{55}$. Podrían ser obra de alguna versificadora del convento, como sucede cuando son agasajadas las cinco monjas capuchinas que en enero de 1710 salen de Madrid para fundar en Lima. Durante su viaje de Madrid a Cádiz se alojan si pueden en otros conventos y a veces son recibidas o despedidas con cantos de las hermanas: en Illescas las clarisas las llevan al coro a ver el nacimiento (día 3 de enero) y les cantan «sus tonitos»; y en las capuchinas de Córdoba, a su partida «las jovencitas con su maestra (quien las había compuesto unos romances a nuestra llegada) se pusieron en dos coros cogiéndonos en medio y cantaron como unos ángeles ${ }^{56}$.

Por lo expuesto hasta ahora podría creerse que la poesía conventual solo estaba hecha para ser usada en comunidad y durante las celebraciones, pero sería una visión muy parcial. "Devota ocupación ha sido de muchos santos y personas espirituales componer algunos versos o para cantar a Dios alabanzas o para avivar con su armonía sus fervorosos afectos. El ejemplar tenemos en el penitente Rey David, en N. S. P. san Francisco, que en diversas lenguas compuso varias canciones y en otros muchos santos y santas ${ }^{57}$. En efecto, dejando atrás

53. Samuel Eiján, op. cit., p. 109-113 y 263-265, no da fecha precisa para estos actos, pero sitúa el acontecimiento en el siglo XVII.

54. BNE, Ms. 3741, p. 204-208; aunque sin datación, el manuscrito se acabó de copiar en 1735.

55. Ibid., BNE, Ms. 3741, poemas en p. 323-327, 753-762, 763-768 y 798-805.

56. Rubén Vargas Ugarte, Relaciones de viajes (siglo XVI, XVII y XVIII), Lima, Instituto de Investigaciones Históricas, 1947, p. 273 y 288 respectivamente. También las reciben con cantos y música en varios conventos portugueses, por ejemplo en Elvas, p. 325.

57. Se trata del texto con el que presenta las poesías de Catalina de Jesús, colocadas al final 
del lejano antecedente bíblico, al que a veces se suma el canto de la Virgen, a partir de la leyenda mayor de san Francisco escrita por san Buenaventura, se atribuye a este santo el inicio de la tradición de usar la poesía como parte de la expresión de un profundo sentimiento religioso, que se manifiesta por medio del canto. Es una tradición que se perpetúa en la orden franciscana y que encuentra dentro y fuera de ella prácticas y reflexiones teóricas ${ }^{58}$, por lo que sirve a los biógrafos para justificar en sus textos la inclusión de algunos poemas de estas monjas ejemplares, cuya calidad poética minimizan:

Los versos y poesía de sor María Francisca no tienen otra industria que la del amor, y de ellos se puede dezir lo que S. Gerónymo dezía: "Son no más que dulzuras de la voz, que animadas del amor hieren a la Alma" [...] Assí componía versos sor María Francisca, diziendo no versos de artificio sino desatinos santos ${ }^{59}$.

Lo mismo recalca el biógrafo de Jerónima de la Ascensión, que componía versos «encendida en el amor divino, quando salía de la bodega del buen vino (como dize la esposa de los cantares) y de lo ardiente de la contemplación, deshecho en afectos su corazón, sin aver estudiado el arte poética, hazía y dezía a su querido y amado esposo versos fervorosos..... ${ }^{60}$. Sin embargo, no todos los poemas que luego edita responden a ese fuego interior, porque se destinan claramente una ocasión social: «A la adoración de los reyes unas religiosas» o son villancicos de navidad, con un estribillo de coro, lo que excluye esa aparente entrega a la poesía repentina por una emoción intensa. Subrayar la falta de artificio y la ausencia de arte poética no es solo una estrategia para debilitar la posición autorial trasladándola a Dios, sino para resituar estos poemas en una esfera propia, como señala Elisabetta Graziosi : "Sostanzialmente una scrittura estranea alla Repubblica delle lettere che ha invece una forte istanza di rientrare in un'altra repubblica: quella militante della santità (vera o affettata, riconosciuta ufficialmente o passata sotto silenzio, questo è un altro affare) ${ }^{61}$. Esta condición no será aplicable a todos los poemas escritos por monjas, pero sí a los que están ligados a una condición de vida modélica de santidad. Son ejemplos de estos versos los que dirigen directamente a Dios, como expresión de profundos sentimientos amorosos, Ana de San Joaquín, que se desahoga en

de su biografía y casi como apéndice incómodo a la misma, Juan Bernique, Idea de perfección y virtudes. Vida de la V. M. y sierva de Dios Catalina de Jesus,y San Francisco..., Alcalá, Francisco García Fernández, 1693, al fin, hojas sin numerar.

58. Vid. Samuel Eiján, op. cit., p. 2-15; y Emilio Orozco, op. cit., p. 54-74.

59. Roque Alberto Faci, op. cit., p. 250. Intercaladas están las palabras de Teresa de Jesús citadas más arriba, que hacen del amor a Dios la fuente de inspiración poética.

60. Jerónima de la Ascensión, Exercicios espirituales que en el discurso de su vida después que tuvo uso de razón hizo y exercitó, Zaragoza, Miguel Luna, 1661, f. 150r.-v.; los poemas se agrupan justo antes de narrar su muerte, ff. 149-159.

61. Elisabetta Graziosi, «Arcipelago sommerso. Le rime delle monache tra obbedienza e trasgressione», en Ginanna Pomata y Gabriella Zarri (eds.), I monasteri femminili come centri di cultura fra Rinascimento e Barocco. Atti del convegno storico internazionale Bologna, 8-10 dicembre 2000, Roma, Edizioni di storia e letteratura, 2005, p. 148. 
verso "quando no podía ocultar toda la avenida de la sagrada llama» ${ }^{62}$; Isabel de Jesús y Gregoria Francisca de Santa Teresa aquejadas de "ansias»" ${ }^{63}$. Estos son casos de un tipo de poesía que nos es más fácil reconocer como religiosa, porque se desliza hacia el lirismo y la descripción de afectos personales. Es la vena poética que predomina en general en las autoras más apreciadas, desde Teresa de Jesús a María de la Antigua, las hermanas Sobrino, Luisa Manrique de Lara o las portuguesas Violante do Céu y María Magdalena Eufemia da Glória.

Una forma extrema de esta función expresiva del desahogo es la que relaciona la poesía con el sufrimiento, mucho más frecuente de lo que pudiera creerse. No es raro que las hagiografías muestren cómo las monjas piden que se les canten o reciten coplas cuando la muerte está próxima. La existencia de una tradición consolidada en ciertas hagiografías apunta que se trata de un topos narrativo que subraya un aspecto fundamental para culminar adecuadamente toda vida heroica o con visos de santidad: la buena disposición para la muerte. San Francisco ofrece un antecedente muy ilustrativo al entonar un salmo en sus últimos momentos, justo antes de expirar, pero el modelo no limita su influjo a la tradición franciscana. Sor Hipólita de Jesús Rocaberti, dominica, canta a una imagen de un niño Jesús que le han llevado a la celda ${ }^{64}$, sor María de Jesús, en trance de muerte, pidió a la abadesa: "Madre, mande V. R. que traigan el harpa y me canten la gloria, y algunas cosas que levanten el espíritu", lo qual se hizo y la sierva de Dios lo agradeció por señas... ${ }^{65}$; e Isabel de la Cruz, carmelita descalza en Alcalá de Henares, cuando cree que le queda poco para morir:

mostrava tantas ansias de ver a Dios que hacía coplas muy sentidas llamando la muerte y estando ya muy cercana a ella hiçe esta:

Di qué sientes coraçón
pareçe que estás de muerte
si esto es çierto, con raçón
llamaré vida mi suerte ${ }^{66}$.

Aun sin estar en trance de muerte, la poesía y el canto se consideraban una forma de aliviar el dolor y alegrarse, al modo de Mariana de San José, que durante una noche con dolores se desahoga escribiendo «una carta de amorosas quexas al Señor ${ }^{67}$. Además de esa función ennoblecedora de la imagen de la

62. Buenaventura de Arévalo, op. cit., p. 173.

63. Isabel de Jesús, op. cit., p. 185; Diego de Torres Villarroel, op. cit., p. 244.

64. «Hallándose a solas y sin registro de las religiosas desahogava su coraçón y sus dolores cantándoles salmos, antífonas y dulces cánticos», Antonio de Lorea, La Venerable Madre Hipólita de Jesús y Rocaberti, religiosa de la Orden de N. P. S. Domingo. Epitome de su prodigiosa vida, virtudes y admirables escritos, Valencia, Vicente Cabrera, 1679, p. 194.

65. Manuela de la Santísima Trinidad, op. cit., p. 267.

66. Relaciones sobre la vida de religiosas primitivas en los monasterios de Castilla la Nueva de la Orden del Carmelo Reformado, siglo XVII, BNE, Ms. 7018, f. 387r.

67. Alonso Villerino, op. cit., II, p. 18. 
monja que se santifica aceptando el dolor, no se puede obviar que la asociación entre la música y la enfermedad estaba muy difundida y la idea de que la música aliviaba los males del espíritu y también podía sanar los del cuerpo tenía una tradición clásica. El rey David, Aristóteles, Pero Mexía, Covarrubias, entre otros, expresan esta creencia ${ }^{68}$, que nuestras monjas llevan de diverso modo a la práctica. Mariana de Jesús, aun ocupándose de la cocina, por las tardes buscaba un rato libre para visitar a las enfermas:
para lo qual havía puesto unas cuerdas de guitarra en una tablica y con aquel género de instrumento tocaba y dávales música, que las alentava porque tenía una voz sonora y suave y assí les dezía: «Hermanas ya viene la música, nadie esté triste...» «Escuchen - decía con mucha gracia- esta poesía, que es casera y se ha hecho esta mañana alrededor de la lumbre» ${ }^{69}$.

Lo mismo hacía Isabel de la Cruz, carmelita descalza de Alcalá de Henares, que para atender a las enfermas y sanas «andava buscando invençiones y conpuniendo festecitas para alegrarlas y en las oras de recreación las entretenía con tanta suavidad y graçia que las ofiçialas no vían lacra de desocuparse para venir goçar de su conbersaçión » ${ }^{70}$. En una vuelta de tuerca típica del gusto barroco por las escenas intensas, se alcanzan pinceladas truculentas cuando Sor Micaela de Jesús canta una coplilla mientras le están cortando el brazo y todas sus compañeras lloran: «En el molino de amor/ se deshace mi alma con este favor ${ }^{71}$; o Beatriz María de San Juan Evangelista, parapléjica al final de su vida, «mostró tal gozo que viéndose en aquella prisión cantava lo que se sigue: "Prisionero mío/ presa me tenéis/ no quiero soltaros/ ni que me soltéis"»" ${ }^{72}$.

\section{El PAISAJE SONORO DE LOS CONVENTOS}

A pesar de que imaginamos los conventos como lugares de recogimiento y silencio por la exigencia de la regla, el repaso a las coplas y versos compuestos por las monjas muestra que en ellos había lugar al bullicio. Sin duda, el carácter de algunas religiosas especialmente cantarinas contribuía a ello, poniendo notas de coplilla en ocasiones de todo tipo o en sus tiempos de soledad, de ahí la referencia a la gracia que mostraban en las recreaciones alegrando a sus hermanas. Pero esa espontaneidad no se da en todos los lugares ni ocasiones, puesto que los espacios destinados a los ritos (la capilla y el coro) nunca son mencionados para estos cantos, que tienen lugar en la celda, el refectorio, la sala,

68. Vid. Luciano López Gutiérrez, Portento y prodigios del Siglo de Oro, Madrid, Nautilus, 2012, p. 251-258, que dedica un capítulo al poder de la música, aunque en ningún caso se refiere a ejemplos como los aquí aducidos, que hubieran sido una buena muestra de sus tesis.

69. Vida, op. cit., ff. 26v-27r.

70. Relaciones sobre la vida de religiosas primitivas, op. cit., f. 384r. Biografía sin fechas, aunque posiblemente anterior a 1650, ya que el monasterio fue de los primeros que fundó santa Teresa.

71. Manuela de la Santísima Trinidad, op. cit., p. 259.

72. Alonso Villerino, op. cit., II, p. 487. 
la enfermería, los pasillos o corredores (el claustro, seguramente) o el jardín ${ }^{73}$. Es decir, lo que podríamos considerar espacios de una ritualidad atenuada.

El canto, con la poesía devota que llevaba asociada, encuentra su espacio preferente en las celebraciones de festejos de todo tipo, entre las que podríamos calificar «de gozo». Hay una cultura de la fiesta que integra lo poético (celebraciones) en diversos grados y maneras: el recibimiento y despedida, el santo patrono, la profesión religiosa, la navidad o la pascua de resurrección, que se prestan a montajes extraordinarios. También hay una cultura donde la poesía y el canto se relacionan estrechamente con el estado del espíritu, bien cuando se le atribuye un origen divino y se permite en circunstancias aparentemente extemporáneas, bien cuando debe alegrar el ánimo en momentos de penalidad. Para las celebraciones existen a veces actos formalizados por medio de una cierta tradición ritual reconocida por el convento, a los cuales se puede añadir la expresión popular, individual o colectiva, de la monja versificadora. Estos ritos muestran grados diversos de elaboración y riqueza que diferencian los conventos incluso dentro de la misma orden, tal como se desprende de la comparación entre las franciscas descalzas granadinas y las de Salamanca. Los medios materiales, la cultura del entorno urbano y seguramente la extracción social de las monjas serían factores decisivos en la configuración de estos actos, como lo era para la producción de pliegos sueltos en tomas de velo. Muchas de las celebraciones caben bajo la muy descriptiva expresión de «divertimento doméstico» que emplea Isabel Morujão $\mathrm{o}^{74}$, en tanto que se confía a la improvisación o al ingenio y sobre todo porque nunca tiene el propósito de trascender la circunstancia para la que nace ni llevarse fuera del círculo familiar. Son, por lo tanto, actividades en las que solo participan las monjas y que esperan una recepción benévola, sin exigencias artísticas o culturales.

Esa falta de expectativas en cuanto a la calidad se concreta en una poesía que nace de la oralidad y muere en ella en la mayor parte de los casos. De hecho debería sorprendernos que se lleguen a poner por escrito y conservar algunas de estas coplas, puesto que su función era estrictamente circunstancial y sus autoras dicen haberlas compuesto (¿y escrito?) para un consumo inmediato que desdeña toda pretensión de perpetuación. Surgen de una repentización a través de la cual el sujeto poético y el yo real se identifican sin fisuras, representando la copla los sentimientos de la autora, pero al hacerse en voz alta se convierten en un bien colectivo y la comunidad los puede hacer suyos. Quizá esa tradición, la de la memoria colectiva, sea la que salve parte de estas composiciones y permita que se trasladen al papel, pero también la que difumina autorías, porque los poemas pueden ser atribuidos sin mayor dificultad a una u otra mano e incluso después de cantados y asimilados, confundirse como propios ${ }^{75}$.

73. Francisca del Santísimo Sacramento va cantando una coplilla por el jardín, Miguel Batista de Lanuza, Vida de la sierva de Dios Francisca del Santissimo Sacramento Carmelita Descalza, Pamplona, José Joaquín Martínez, 1727, p. 159.

74. Op. cit., p. 106.

75. Uno de los casos más característicos es el "Entra en el sol soledad», que se atribuye a Luisa de la Ascensión y a María de la Antigua, vid. Luis Vázquez, «Poemas sanjuanistas fuera del 
Por otra parte, ese entorno de creación y recepción marca las características de los textos, que estudiaremos con detalle en un futuro trabajo. Ahora bien, es evidente que muchos responden a patrones métricos y verbales tradicionales, que al ser usados de modo habitual dentro del grupo no solo sirven al didactismo por el contenido, sino que son portadores de un modelo compositivo fácilmente imitable, incluso pensado para generar esa imitación ${ }^{76}$. Así es posible que se conviertan en versificadoras quienes no tienen ninguna formación, dado que es una poesía entregada a la imitación y al uso colectivo por variación de algunos componentes, sin intención alguna de originalidad. Ese destino efímero puede ser burlado bien por la voluntad de un tercero, que rescata esos poemas para una hagiografía o una historia conventual, o a veces por la misma autora, que para dotar de trascendencia a sus poemas los comenta o presenta como parte de un mensaje divino superior a su propia voluntad. Isabel de Jesús, en su Tesoro del Carmelo escondido, actúa bajo el mandato y la superior utilidad de sus textos para dignificar sus poemas por medio del comentario: "porque tengo por sin duda ha de ser de mucho provecho para las almas espirituales la explicación que me ha mandado V. Md. la ponga al pie de todas las canciones» ${ }^{77}$. Una dignificación parecida, si no en la república de las letras sí en el universo de la santidad, pretende sor María de la Antigua, que construye su texto como mera trascripción de las palabras de Dios: «Esta palabra entendí assí y todas las demás que en los romances van ninguna es artificiosa ni buscada de propósito para que en ellas quadre, antes son todas salidas del coraçón con los vivos sentimientos que en él causa el amado» ${ }^{78}$. A pesar de nacer del mismo magma conventual, ambiciona elevar sus poemas y su obra en prosa por encima de lo comunitario para convertirlos en textos únicos, dignos de memoria y de una autoría diferenciada.

Procedan de una voluntad autorial o de una simple efecto imitador, de una monja visionaria o de una mujer formada con vocación poética, hayan quedado en los muros conventuales o se hayan publicado, construyan una estética propia o sean una coplilla sin ningún valor literario, todos estos poemas encuentran su sentido en un entorno conventual que comparten autoras y receptoras, donde tuvieron su sentido originario y sus posibilidades últimas de pervivencia. Más adelante tendremos que estudiar otros aspectos, pero sin conocer sus circunstancias de producción y consumo poco podríamos entender de esta poesía.

Carmelo", Estudios, XXXXVII, 137, 1982, p. 149-198; otro muy significativo es el de Isabel del Jesús, que escribe a su confesor sobre unos poemas: «me dispuso V. Md. escribiese aquí unos versos que hize, que puedo decir de verdad ser míos, aunque V. md. tenga noticia de averlos visto antes...", op. cit., p. 642; se trata de liras de Cecilia del Nacimiento.

76. Isabel Morujão, op. cit., p. 566, dice cómo una de las funciones de la literatura de clausura femenina es ser espejo de la perfecta religiosa. En efecto los estados del alma y sus matices, que pueden ser susceptibles de una tipología y también de forma de manejarlos, aparecen en estos poemas.

77. Op. cit., p. 630.

78. Op. cit., p. 596. 